of man and cobra more rare, I should say, than aggressive snakes. Had the snake been there before the man entered the latrine it is only natural to suppose he would have seen it, and judiciously bolted. And, above all, we have the man's own statement, and there is no reason why he should not be believed.

Regarded in a medical light, the case is not without interest. (1) The incised nature of the wound, so unlike that which the fang of a snake would inflict; from the position and appearance of the wound I should never have thought it to be a snake-bite. (2) It rarely occurs that an opportunity of early treatment is given in these cases, and the chances of saving life are fearfully diminished if many minutes elapse before remedial measures are adopted. About three minutes elapsed from the time of injury to the application of the acid, and it will be seen of how very little avail treatment was in this case. (3) The suddenness and calmness with which the man died (to me inexplicable) gave no time to try the injection of ammonia or any other of the specifics. I should say the dose of poison was too strong for any " remedy." Why the poison should have remained latent in the system for a little more than an hour without giving the least indication of its presence, and then acting with almost instantaneous effect, I am not prepared to state. I need not say that the man was in perfect health previous to this accident. His friends would not allow a post-mortem examination.

Many of the cases of snake-poisoning reported as cured have been, I believe, bites of non-poisonous snakes. Natives know the symptoms of snake-poisoning. When bitten and they do not see the snake, as frequently occurs at night, or when the snake escapes and its species cannot be determined, they at once assume it to be poisonous, and forthwith develop many of the symptoms. I was called about ten months ago to see a native female servant who bad been bitten whilst walking without shoes in the garden after dark, The snake seized ber by the great toe of the left foot, and inflicted two punctured wounds. The woman gave herself up to certain death. I did not see her for nearly an hour after she had been bitten. She then presented some of the symptoms. She wanted to sleep, she talked as if delirious, her skin was cold and clammy, and pulse weak. Effects of fright? I had nothing at hand but brandy, which I gave her. I spoke to her encouragingly. Hope came back: the symptoms disappeared. She lay down and slept till morning, and awoke quite well with the exception of having a sore toe. The suake evidently bit with a will, and, had it been poisonous, would have bitten with fatal effect. If I had a pet antidote, and had used it in this case, I might in all good faith have registered this as another cure of snake-poisoning.

Kirkee.

\section{A CASE OF CHARBON.}

\section{BY JOSEPH ROGERS, M.D.}

ON Thursday, the 26th ult., I was called at 9 P.M. to see Mrs. H- the wife of a respectable tradesman residing in this neighbourhood. On reaching the house the husband informed me that his wife had been ill some three days, and that she, being a devotee of the homcopathic heresy, had been under the care of some person of that fraternity; that feeling dissatisfied with. the little which was being done for her, and alarmed at her condition, he had sent for me. On entering her bedroom I observed her lying on her back in bed evidently dangerously ill. On examination I found that the lower lip was enormously swollen, everted, and perfectly black. About half an inch from the lip on the right side, there was a small pimple with a black bead. On touching the chin. I found it tense as brawn, which tenseness extended to the ear on each side, and descended as far as the cricoid cartilage. She protruded her tongue with much difficulty; it was coated with a white fur, the edges being red. Pulse 120; skin hot and dry, communicating a very unpleasant sensation to the fingers.

Though quite unprepared to see such a case, I immediately diagnosed it as charbon. As the bowels were confined, I ordered a mild aperient; also, disulphate of quinine, two grains; solution of pernitrate of iron, twenty minims; solution of concentrated acetate of ammonia, twenty minims, every three hours; applying over the swelling a charcoal and linseed-meal poultice. I also directed that wine, beef-tea, \&c., should be given freely and frequently. At 8 A.M. of the 27 th I found her state more alarming, her skin covered with a clammy perspiration, pulse 90 and intermittent. I therefore suggested a consultation, and Dr. Anstie was sent for. He agreed with me as to the nature of the case, and prognosticated, as I had done, a fatal termination. At 8.30 A. Mr. the temperature was $102 \frac{1}{2}^{\circ}$, although the skin was moist. It was decided to continue the quinine and iron, omilting the solution of acetate of ammonia, to reapply charcoal poultices, and to repeat the beef-tea, milk, eggs, and brandy every half-hour, or whenever practicable. At noon the pulse had risen to 140 ; skin very hot, and on turning the bed to the light I noticed the dark subcutaneous tissue of the chin and neck showing through the tense white skin.

At each subsequent visit up to 10 P.M. I found her becoming gradually worse, but with intellect unclouded, and to my repeated inquiries as to whether she was in pain, she always replied "No." She died at 3 A.m. of the $28 \mathrm{th}$.

I have subsequently learnt that, whilst sitting in a first-floor room with her children on the previous Sunday, the window being open, a large bluebottle fly settled on her chin and stung her sharply. She brushed it off and tried to kill it. Subsequently a pimple developed on the site of the sting, which increased in size, and became so troublesome as to induce her to send for her homoopatbic attendant on Tuesday, on which day she also saw a friend, a French lady, who told her she had better be careful, as the pimple reminded her of the disease called charbon, which she had seen in France, which was due to the poison of a $\mathrm{Hy}$, and which would destroy life in four or five days. My patient laughed at this, so thoroughly at that time was she ignorant of the relation existing between the sting of the fly and her fatal illness.

Dean-street, Soho.

NOTES OF

\section{A CASE OF ASSUMED AMAUROSIS.}

Bx JAMES H. STOWERS, M.R.C.S. ENG., OPHTHALMTC HOUSE-SURGEON TO ST. BARTHOLONEW'S HOSPITAL.

MARTHA D-, aged fifteen years, was admitted into the hospital on June 3rd, 1873, under the care of Mr. Power. The history given was that the patient had but a short time since been in one of Mr. Holden's wards for erythema of the left leg and arm, the precise cause of which, however, was not very clearly shown. She said that as long as she could remember she had been obliged to bring objects very near to her right eye to see them distinctly, but that vision suddenly left her during the time she was under treatment for her leg, \&c. Her peculiar behaviour had been previously noticed when in Lawrence ward.

Dropping of the right upper lid then occurred, though when spoken sharply to, with a pretended effort, she could raise it, but again to let it fall. On examination, both eyes were found to be in exactly the same condition, and to all appearances quite healthy. Several careful ophthalmoscopic examinations were made, notwithstanding the difficulty experienced in making ber fix the eyes in any one position, in consequence of the pain that she said was present in the right globe. The optic dises on both sides were not quite so clearly defined as they should be, but nothing abnormal in the media, \&c., retina or vessels of eitber fundus, could be seen. The irides acted perfectly when stimulated. She was: constantly seen to be rubbing the lids, when closed, with her fingers. The patient is a wellnourished, fair-haired girl, and presents in her manner and behaviour many characteristics of the hysterical type.

A mixture containing tincture of valerian with tincture of hyoscyamus and camphor mixture was ordered to be taken three times a day.

The right vision, when a very bright light is used and the left eye covered; is totally absent, though a fourteen- 